\title{
The Modulation of Gulf Stream Influence on the Troposphere by the Eddy-Driven Jet $\mathscr{O}$
}

\author{
RHYS PARFITT \\ Florida State University, Tallahassee, Florida, and Woods Hole Oceanographic Institution, Woods Hole, Massachusetts \\ YOUNG-OH KWON \\ Woods Hole Oceanographic Institution, Woods Hole, Massachusetts
}

(Manuscript received 19 April 2019, in final form 6 February 2020)

\begin{abstract}
This study suggests that the Gulf Stream influence on the wintertime North Atlantic troposphere is most pronounced when the eddy-driven jet (EDJ) is farthest south and better collocated with the Gulf Stream. Using the reanalysis dataset NCEP-CFSR for December-February 1979-2009, the daily EDJ latitude is separated into three regimes (northern, central, and southern). It is found that the average trajectory of atmospheric fronts covaries with EDJ latitude. In the southern EDJ regime ( $19 \%$ of the time), the frequency of near-surface atmospheric fronts that pass across the Gulf Stream is maximized. Analysis suggests that this leads to significant strengthening in near-surface atmospheric frontal convergence resulting from strong air-sea sensible heat flux gradients (due to strong temperature gradients in the atmosphere and ocean). In recent studies, it was shown that the pronounced band of time-mean near-surface wind convergence across the Gulf Stream is set by atmospheric fronts. Here, it is shown that an even smaller subset of atmospheric fronts - those associated with a southern EDJ-primarily sets the time mean, due to enhanced Gulf Stream air-sea interaction. Furthermore, statistically significant anomalies in vertical velocity extending well above the boundary layer are identified in association with changes in EDJ latitude. These anomalies are particularly strong for a southern EDJ and are spatially consistent with increases in near-surface atmospheric frontal convergence over the Gulf Stream. These results imply that much of the Gulf Stream influence on the timemean atmosphere is modulated on synoptic time scales, and enhanced when the EDJ is farthest south.
\end{abstract}

\section{Introduction}

In the midlatitudes, the traditional view has been that the ocean is rather passive in terms of large-scale atmospheric forcing (e.g., Frankignoul and Hasselmann 1977; Seager et al. 2002). This is in large part due to the multitude of studies demonstrating the covariability between the atmospheric circulation and midlatitude sea surface temperature (SST) fields to be characterized by the atmosphere leading the ocean (e.g., Deser and Timlin 1997), with much of the midlatitude SST variability on decadal time scales or shorter considered as a response to stochastic atmospheric forcing (e.g., Frankignoul et al. 1997; Barsugli and Battisti 1998). In

\footnotetext{
Supplemental information related to this paper is available at the Journals Online website: https://doi.org/10.1175/JCLI-D-190294.s1.
}

Corresponding author: Rhys Parfitt, rparfitt@fsu.edu comparison, identified responses of the extratropical atmosphere to midlatitude SST anomalies have been relatively modest (e.g., Ciasto and Thompson 2004; Wills et al. 2016). However, most of the studies employing this stochastic atmospheric forcing framework have used rather low-resolution observational or model data that cannot properly capture frontal or mesoscale variability.

With the relatively recent availability of high-resolution satellite measurements and increased climate model capability, many recent studies have demonstrated a more active role for the ocean (e.g., Hewitt et al. 2017; Small et al. 2018). This is particularly true over the western boundary currents (WBCs), where it has been shown that SST variability at monthly and longer time scales is driven by internal ocean processes ("oceanic weather"; Bishop et al. 2017) on spatial scales less than $500 \mathrm{~km}$. In addition, a better-resolved ocean is seen to offer increased near-term climate predictability (Siqueira and Kirtman 2016), and drive deep ascent as high as $10 \mathrm{~km}$ 
into the atmosphere (Kobashi et al. 2008; Tokinaga et al. 2009). This deep ascent results in a striking imprint of the meandering ocean fronts on the time-mean wind convergence throughout the depth of the troposphere (Feliks et al. 2004, 2007; Minobe et al. 2008, 2010), suggesting a pathway for the ocean to trigger planetary wave responses (e.g., Lee et al. 2018).

Mechanistically, this oceanic imprint has traditionally been associated with a time-mean atmospheric response associated with either a boundary layer pressure adjustment mechanism (Lindzen and Nigam 1987; Minobe et al. 2008; Nkwinkwa Njouodo et al. 2018) in which fluxdriven spatial pressure gradients drive secondary circulations (Wai and Stage 1989) or the momentum mixing anomalies induced down through the boundary layer by differential SST values (Hayes et al. 1989; Wallace et al. 1989). However, recent studies have shown that this band of time-mean wind convergence is dominated by synoptic storms (Parfitt 2014; Parfitt and Czaja 2016; O'Neill et al. 2017) and is in fact set by atmospheric fronts embedded within them (Parfitt and Seo 2018). More specifically, maxima in the time-mean wind convergence located on the warm side of the strong SST gradients are shown to result from the local intensification of atmospheric frontal convergence there, which Parfitt and Seo (2018) hypothesize is due to the large gradients in surface sensible heat flux ("thermal damping and strengthening"; see Fig. 4 in Parfitt et al. 2016). These results hint that atmospheric frontal variability over WBCs can modulate the oceanic influence on the troposphere. If so, linking this frontal variability to large-scale climate drivers can help to better understand the role of the ocean in forcing midlatitude climate.

Indeed, atmospheric fronts themselves are a manifestation of transient eddies. These transient eddies force a westerly "eddy-driven" jet (EDJ) through momentum and heat that extends through the depth of the troposphere. It therefore stands to reason that variations in the EDJ should also modulate the depth of WBC forcing on the atmosphere. This is of substantial importance, as in the North Atlantic region specifically indicators of the EDJ show a large coherence with largescale weather indices such as the North Atlantic Oscillation and east Atlantic teleconnection pattern (Woollings et al. 2010). Additionally, variations in its strength and location have been linked to basinwide occurrences of high-impact blocking events (Woollings et al. 2018). As such, investigating the characteristics of atmospheric fronts with respect to the compounding relationship with the EDJ and the Gulf Stream SST front could help us to better understand the interplay between the midlatitude ocean and large-scale climate patterns, and provide further motivation for ongoing research into correcting the known issue of EDJ biases in current general circulation models (e.g., Kwon et al. 2018).

The main aim of this study is to explore the relationship between the North Atlantic EDJ, the Gulf Stream SST front, and atmospheric frontal variability in the context of how deep the Gulf Stream influence extends into the troposphere. The datasets and diagnostics used in this study are described in section 2. Sections 3 and 4 discuss the relative roles of the EDJ and Gulf Stream front in determining the variability of atmospheric frontal frequency and circulation. Section 5 illustrates the implications of these roles for the depth of Gulf Stream influence on the troposphere. A summary is provided in section 6 .

\section{Data and methods}

\section{a. Datasets}

The analysis in this study focuses on Northern Hemisphere wintertime [December-February (DJF)]. The dataset used is the National Centers for Environmental Prediction Climate Forecast System Reanalysis (NCEPCFSR) product (Saha et al. 2010) from 1979 to 2009, with global atmospheric spectral resolution T382 $(\sim 38 \mathrm{~km})$ provided on a $0.5^{\circ} \times 0.5^{\circ}$ longitude-latitude grid. NCEP-CFSR is based on a coupled data assimilation incorporating a global ocean model with a horizontal resolution of $0.25^{\circ}$ at the equator. NCEP-CFSR is chosen specifically as SST resolution has been shown to play a big role in determining the extent of the frontal air-sea interaction over WBCs (Masunaga et al. 2015; Vannière et al. 2017), with studies suggesting that an SST resolution of around $0.25^{\circ}$ is required to properly resolve the impact of oceanic fronts on atmospheric eddies (e.g., Smirnov et al. 2015). Indeed, it has been shown that model and reanalysis data with SST resolution below this threshold can systematically lead to a reduction in atmospheric fronts of up to $30 \%$ (Parfitt et al. 2016, 2017a).

\section{b. Diagnostics}

The daily latitude of the EDJ in the North Atlantic is calculated using the zonal wind at $850 \mathrm{hPa}$ following an adapted methodology of Woollings et al. (2010). The daily zonal wind at $850 \mathrm{hPa}$ is averaged across $0^{\circ}-60^{\circ} \mathrm{W}$ and smoothed with a 5-day running mean. The latitude of the maximum amplitude is then taken as the basinwide EDJ latitude for each day. Figure 1a illustrates the distribution of daily EDJ latitudes across DJF 19792009 in NCEP-CFSR. The distribution illustrates a three-peak EDJ structure as expected (Woollings et al. 2010), and these three EDJ "regimes" form a major part 

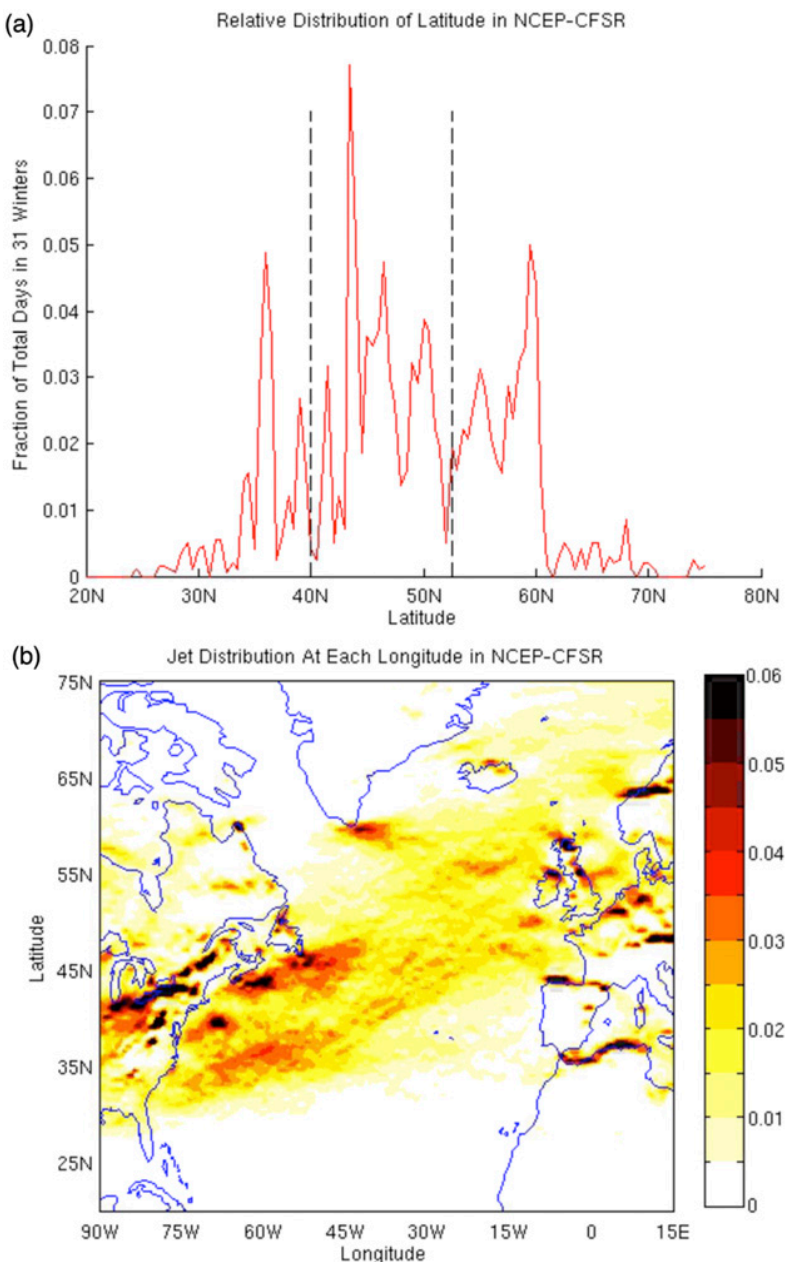

FIG. 1. (a) The distribution in DJF 1979-2009 of daily eddydriven jet latitudes, calculated from the daily $0^{\circ}-60^{\circ} \mathrm{W}$ zonally averaged wind at $850 \mathrm{hPa}$, using NCEP-CFSR. The latitudinal boundaries between the southern, central, and northern eddydriven jet regimes are plotted as dotted lines at $40^{\circ}$ and $52.5^{\circ} \mathrm{N}$ (b) The distribution in DJF 1979-2009 of daily eddy-driven jet latitudes, calculated from a daily zonal wind at $850 \mathrm{hPa}$ at each longitude, using NCEP-CFSR. The shaded value at any point represents the relative frequency with which the eddy-driven jet is found at that latitude, for that particular longitude.

of the analysis in this study and are discussed at length in later sections. As illustrated, the so-called northern-, central-, and southern-latitude regimes of the EDJ are defined in this paper as latitudes greater than $52.5^{\circ} \mathrm{N}$, between $40^{\circ}$ and $52.5^{\circ} \mathrm{N}$, and less than $40^{\circ} \mathrm{N}$, respectively. For DJF 1979-2009, the EDJ is located in these northern, central, and southern regimes for $34 \%, 47 \%$, and $19 \%$ of the time, respectively.

While the three-peak distribution structure resulting from this zonally averaged EDJ calculation is well established and has been heavily linked to weather and climate in both the Euro-Atlantic sector and farther
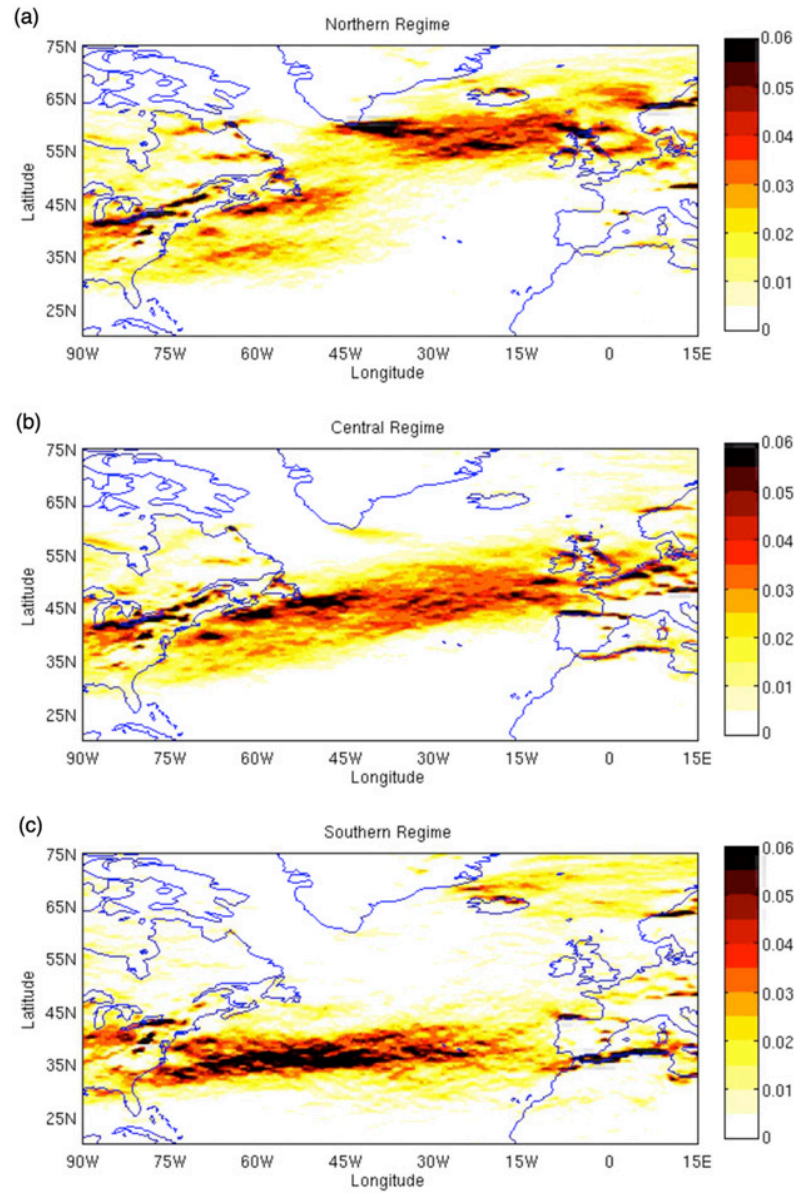

FIG. 2. The distribution in DJF 1979-2009 of daily eddy-driven jet latitudes, calculated from a daily zonal wind at $850 \mathrm{hPa}$ at each longitude, using NCEP-CFSR, in each eddy-driven jet regime. The shaded value at any point represents the relative frequency with which the eddy-driven jet is found at that latitude, for that particular longitude in the (a) northern, (b) central, and (c) southern eddy-driven jet regime.

afield (e.g., Santos et al. 2013; Woollings et al. 2014; Liu and Barnes 2015), it is not immediately obvious that one should expect to observe three regimes at every longitude. This can be seen in Fig. 1b, which uses the same method as above, except no zonal averaging takes place, resulting in a daily EDJ latitude calculated at every longitude. The coherence of the partitioning into three regimes instead becomes clear when one plots the daily EDJ latitude calculated at every longitude for each of the three regimes separately, as in Fig. 2.

For the calculation of atmospheric fronts, the $F$ diagnostic $-F=\zeta_{p}\left|\nabla\left(T_{p}\right)\right| / f\left|\nabla T_{o}\right|$, where $\left|\nabla\left(T_{p}\right)\right|$ is the magnitude of the temperature gradient on pressure level $p, \zeta_{p}$ is the isobaric relative vorticity on that same pressure surface, $f$ is the Coriolis parameter at each latitude, and $\left|\nabla T_{o}\right|$ is a typical scale for temperature 
gradient $0.45 \mathrm{~K}(100 \mathrm{~km})^{-1}$-is used (Parfitt et al. 2017b). Frontal regions are identified every $12 \mathrm{~h}$ at 0000 and 1200 UTC when and where the variable $F$ exceeds a value of 1 at $900 \mathrm{hPa}$ "near-surface fronts" and 2 at $600 \mathrm{hPa}$ "midtropospheric fronts." It is noted that the results in this study are not sensitive to the local time of frontal identification. An example of a near-surface front identified with the $F$ diagnostic can be seen in Fig. 1 of Parfitt et al. (2017b) (see Fig. S1 in the online supplemental material for a midtropospheric example). The appropriate pressure levels for midtropospheric and nearsurface frontal identification were originally chosen following the methodology of Hewson (1998). It is noted that some differences do exist between different objective frontal diagnostics (e.g., Schemm et al. 2015), and a full discussion of the $F$ diagnostic is given in Parfitt et al. (2017b), accompanied by an extensive comparison with the widely used "H98" diagnostic from Hewson (1998). It is noted that using the product of temperature gradient and relative vorticity has also been recommended by Solman and Orlanski $(2010,2014)$ as a metric for general frontal activity. Figure 3 illustrates the atmospheric frontal frequency based on $F$ shown as a fraction of the total period DJF 1979-2009 at (a) 600 and (b) $900 \mathrm{hPa}$ in the Gulf Stream region in the NCEP-CFSR dataset.

The climatology of midtropospheric fronts exhibits a northeasterly tilt, with maxima off the east coast of Canada over Nova Scotia. This general structure is also present for the climatology of near-surface fronts, although there are significant enhancements along the coast due to temperature and vorticity anomalies generated across the land-sea boundaries within the atmospheric boundary layer. These enhancements are commonly identified and are also present in diagnostics of near-surface fronts based solely on temperature [see Parfitt et al. (2017b) for a full discussion]. Away from the coastline, a frontal frequency maximum is identified at $900 \mathrm{hPa}$ along the Gulf Stream SST front.

\section{Preferred paths of atmospheric fronts and EDJ latitude}

The three-peak structure of the North Atlantic EDJ observed in Fig. 1a is frequently discussed in relation to weather patterns in the Euro-Atlantic sector. Figure 4 illustrates the frontal frequency of midtropospheric fronts in NCEP-CFSR for each of the daily jet regimes in NCEP-CFSR. It is observed that the midtropospheric frontal track becomes more northeasterly as the jet shifts poleward, reflecting the expected close relationship between the EDJ and the location of atmospheric fronts. This variability in the tilt and reach of the midtropospheric frontal track is reminiscent of changes one
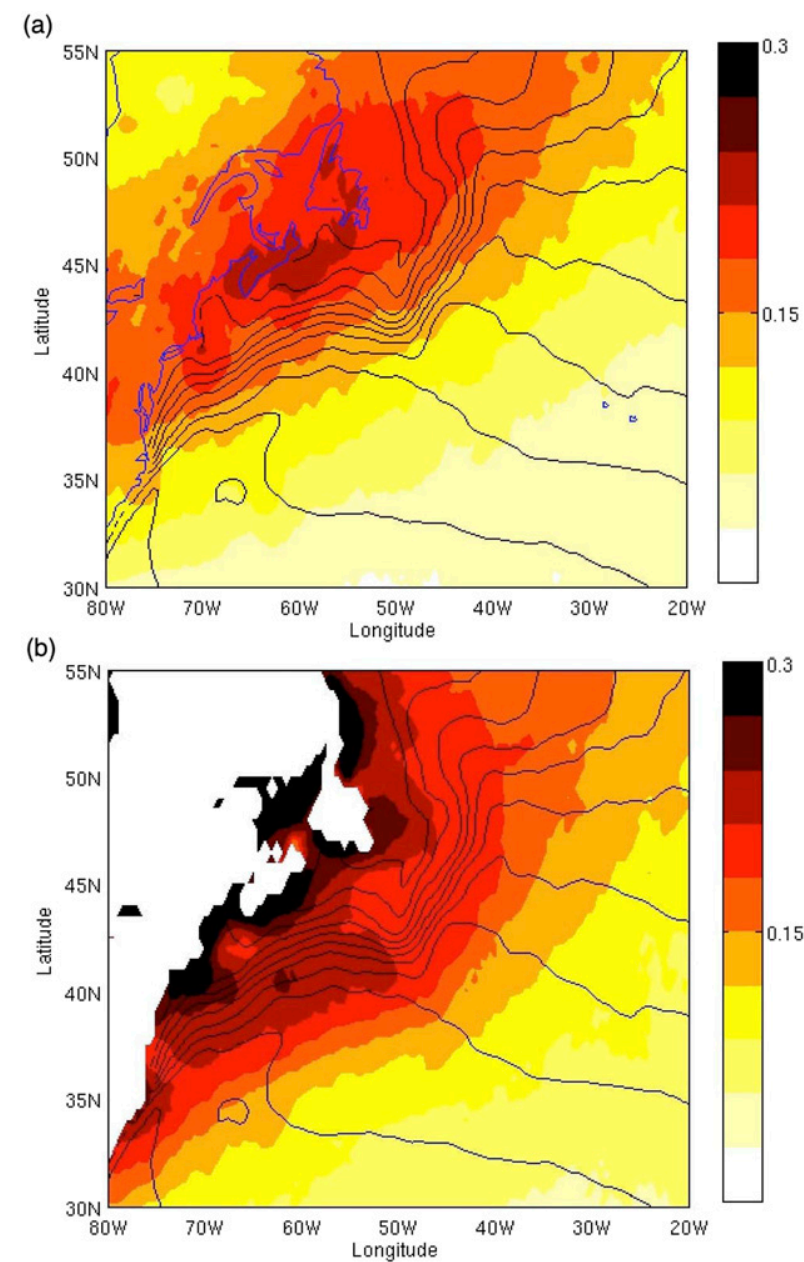

FIG. 3. The frequency of atmospheric fronts based on the $F$ diagnostic in NCEP-CFSR at (a) 600 and (b) $900 \mathrm{hPa}$, shown as a fraction of the period DJF 1979-2009. Mean sea surface temperature (SST) contours in NCEP-CFSR are plotted in black from $2^{\circ}$ to $22^{\circ} \mathrm{C}$ at an interval of $2^{\circ} \mathrm{C}$. At $900 \mathrm{hPa}$ the land has been masked, while at $600 \mathrm{hPa}$ the coastline has been plotted in blue.

might expect from a change in the phase of the North Atlantic Oscillation (NAO), and links between the EDJ, the NAO, and other North Atlantic weather regimes have indeed been identified in recent years (Vautard 1990; Cassou et al. 2004; Woollings et al. 2010; Madonna et al. 2017). The distinction between the midtropospheric frontal tracks in each regime is more clearly illustrated in Fig. 5, which shows the anomalies in midtropospheric frontal frequency in each EDJ regime with respect to the time mean. The anomalies are calculated as regime frequency minus time-mean frequency, and as such positive (negative) values imply more (less) frequent midtropospheric fronts in that regime. Comparison of Fig. 5 with Fig. 3a demonstrates that as a percentage of the time-mean midtropospheric frontal frequency, changes of up to $50 \%$ can be found in each regime. 
(a)

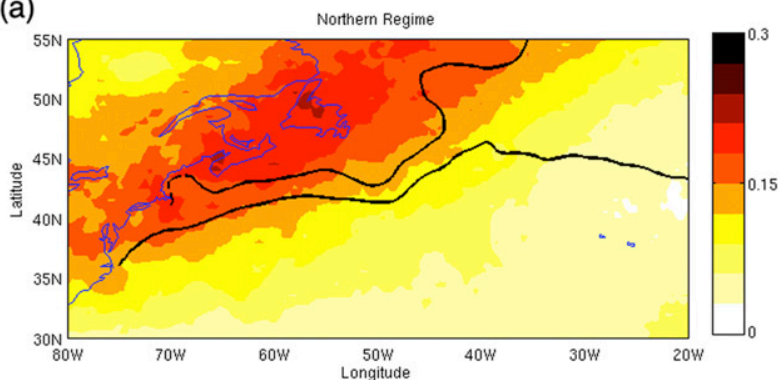

(b)

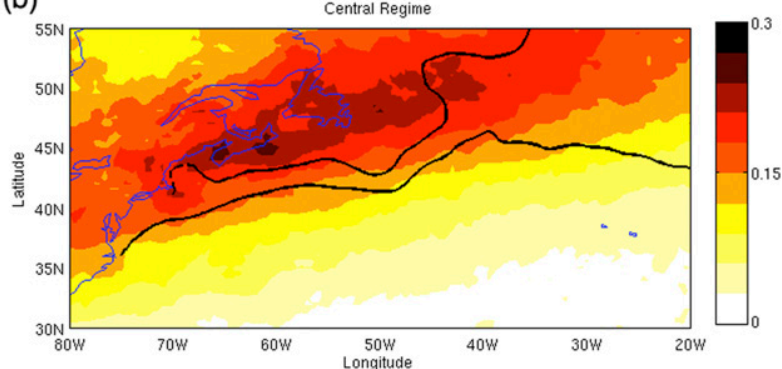

(c)

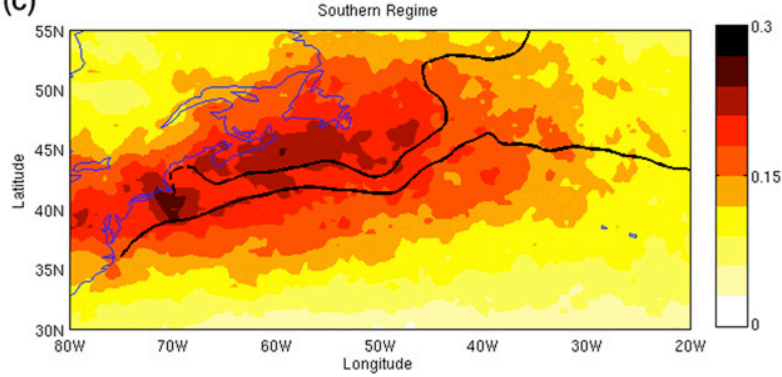

FIG. 4. The frequency of atmospheric fronts at $600 \mathrm{hPa}$ for the days when the eddy-driven jet is in the (a) northern, (b) central, and (c) southern regime. The mean SST contours in NCEP-CFSR are plotted in black for $6^{\circ}$ and $14^{\circ} \mathrm{C}$.

Figure 6 illustrates the frequency of near-surface fronts at $900 \mathrm{hPa}$ in NCEP-CFSR. As aforementioned, at the $900-\mathrm{hPa}$ level enhanced surface effects are apparent for each regime, such as the augmentation of frontal frequency near the coastlines due to temperature and vorticity anomalies generated within the boundary layer across the coastline, leading to maximum frequencies observed in these regions. In general, the nearsurface frontal frequency tends to broadly decrease away from the coastline, although in each regime there is a maximum in frequency extending eastward $\sim 40^{\circ} \mathrm{N}$ along the Gulf Stream, likely caused by the strong associated baroclinicity induced by the sharp SST gradient. However, this frequency maximum along the Gulf Stream is substantially larger for the southern EDJ regime. In other words, the frequency of near-surface fronts over the Gulf Stream front is significantly enhanced when the EDJ is at low latitudes. A potential (a)

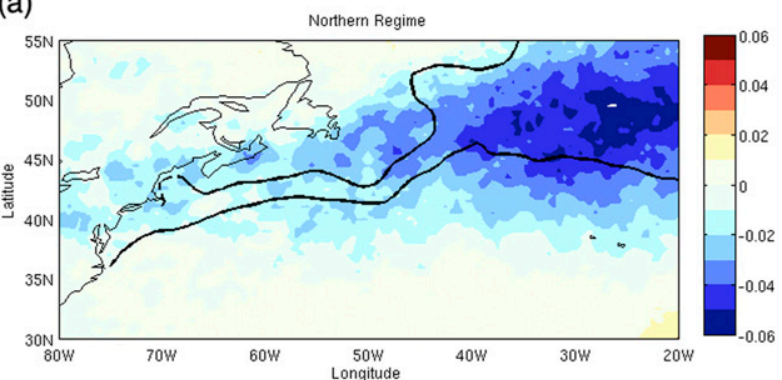

(b)

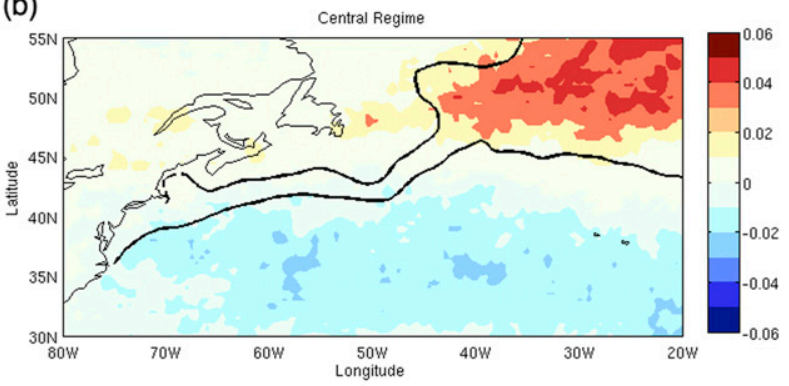

(c)

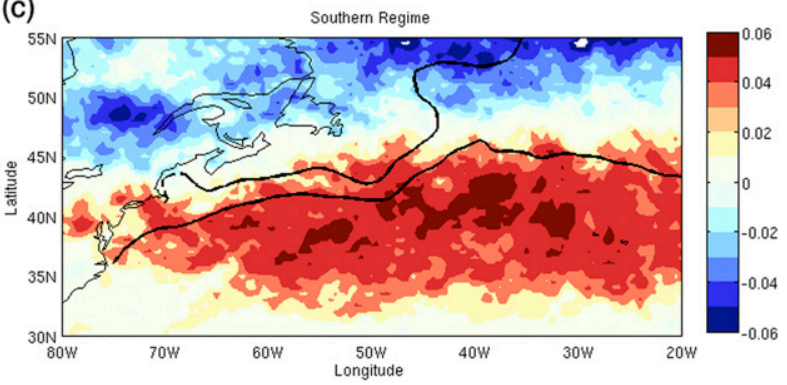

FIG. 5. Anomalies in atmospheric frontal frequency at $600 \mathrm{hPa}$ for the days when the eddy-driven jet is in the (a) northern, (b) central, and (c) southern regime in NCEP-CFSR. Anomalies are calculated as regime frequency minus mean climatological frequency [i.e., positive (negative) values mean higher (lower) frequency in that specific regime than on average]. The mean SST contours in NCEP-CFSR are plotted in black for $6^{\circ}$ and $14^{\circ} \mathrm{C}$.

explanation for this is discussed in later sections. As with midtropospheric fronts, the downstream near-surface frontal track is observed to tilt more northeasterly as the jet latitude increases. The anomalies in near-surface frontal frequency with respect to the time mean are illustrated in Fig. 7. As before, a comparison between Fig. 7 and Fig. $3 \mathrm{~b}$ demonstrates changes of up to $50 \%$ in each regime with respect to the time-mean near-surface frontal frequency.

\section{Variability in frontal air-sea interaction with EDJ latitude}

While the strong coupling between strong SST fronts like the Gulf Stream and atmospheric fronts has been noted in recent years, only one mechanism has been 
(a)

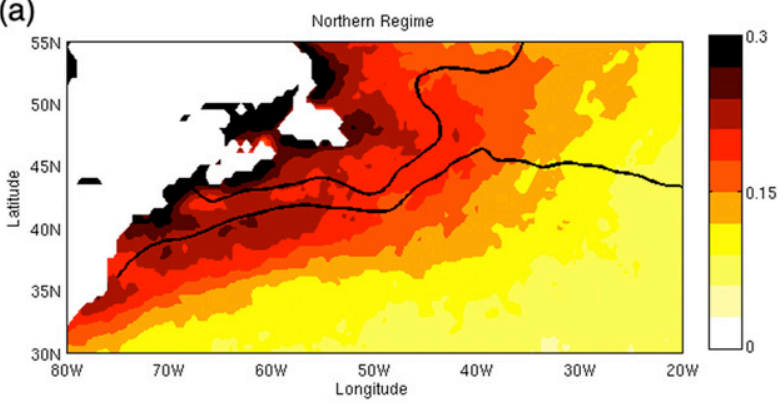

(b)

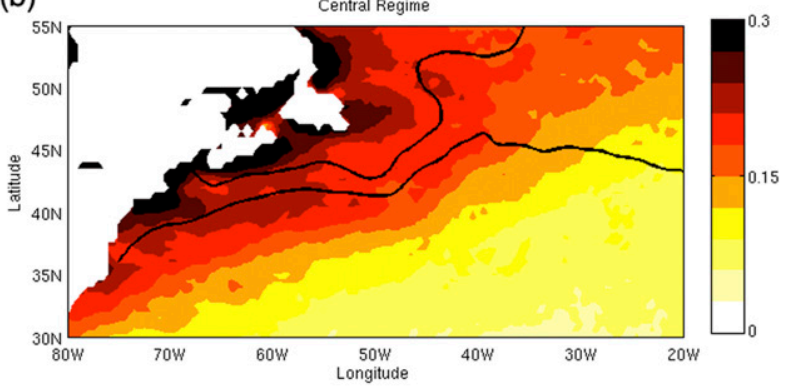

(c)

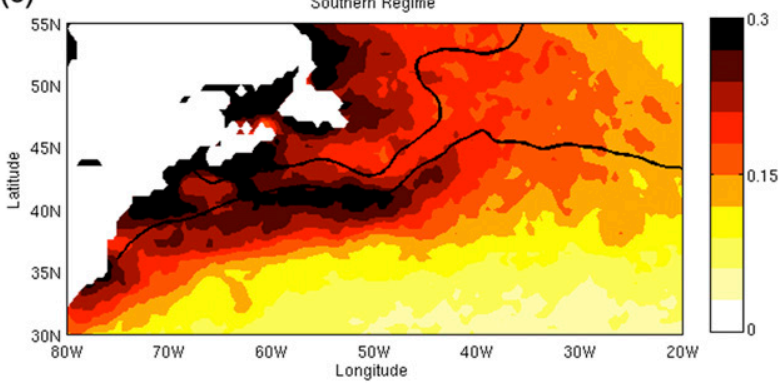

FIG. 6. As in Fig. 4, but for atmospheric fronts at $900 \mathrm{hPa}$.

hypothesized so far regarding their interaction ["thermal damping and strengthening" (TDS); see Fig. 4 in Parfitt et al. 2016]. TDS suggests that the intensification or weakening of atmospheric fronts as they pass over strong SST fronts is predominantly modulated by strong cross-atmospheric frontal sensible heat flux gradients. In particular, a modeling study by Parfitt et al. (2016) found that the significant change in atmospheric frontal frequency occurring in response to a weakened Gulf Stream SST gradient was primarily due to a change in the cross-atmospheric frontal surface sensible heat flux gradient across cold fronts specifically, consistent with TDS. Furthermore, the key role of differential sensible heating in atmospheric frontal formation has been more recently noted over the Kuroshio SST front in a modeling study by Hirata et al. (2019). Given these studies and the significant change in atmospheric frontal frequency with EDJ latitude, it is therefore of interest to apply TDS analysis to each regime individually. (a)

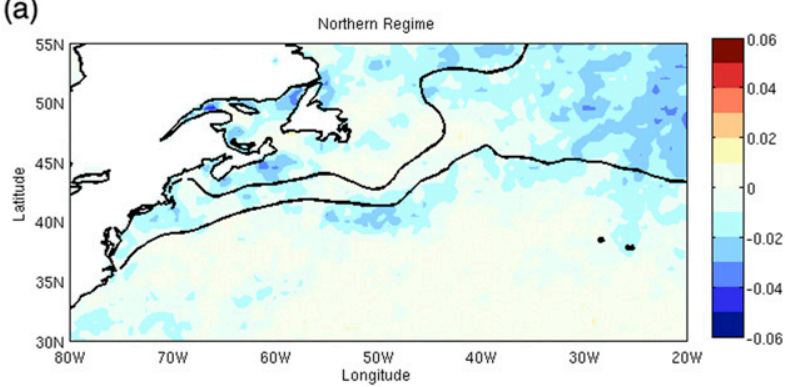

(b)

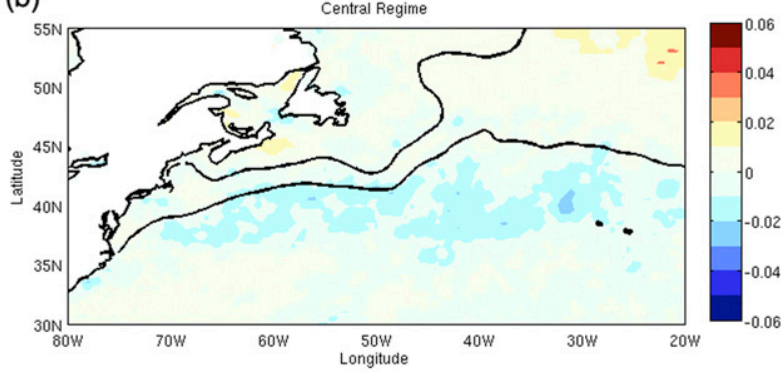

(c)

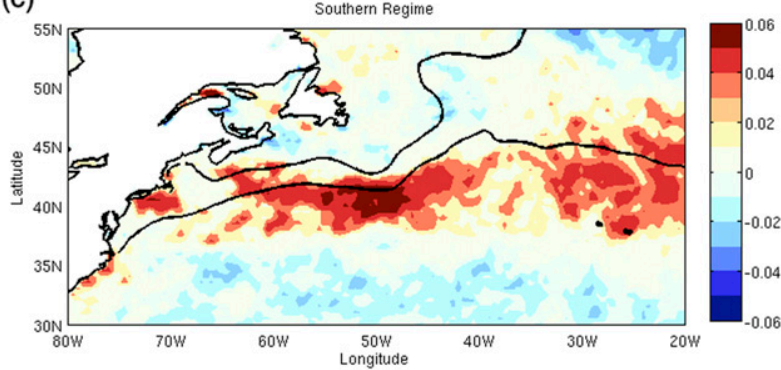

FIG. 7. As in Fig. 5 , but for anomalies in atmospheric frontal frequency at $900 \mathrm{hPa}$.

Figure 8 illustrates the average cross-atmospheric frontal surface sensible heat flux gradient experienced by atmospheric cold fronts at $900 \mathrm{hPa}$ as they pass across the Gulf Stream. Cold atmospheric frontal locations are derived from previously identified atmospheric fronts using the magnitude and direction of front speed as in Catto et al. (2012). The direction of the surface sensible heat flux gradient is directed toward the cold sector such that negative (positive) values indicate that the cross-atmospheric frontal surface sensible heat flux gradient is acting to strengthen (dampen) the atmospheric cold front. In Parfitt et al. (2016), it was noted that significant strengthening is expected along the strongest SST gradient of the GS front with significant dampening on either side, and this is indeed seen in each EDJ regime. The significant similarity between the values in each regime suggests that the TDS effect is primarily set by the oceanic temperature gradient. 
(a)

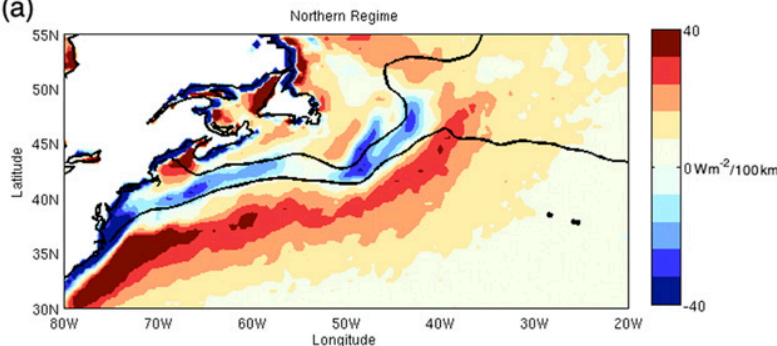

(b)

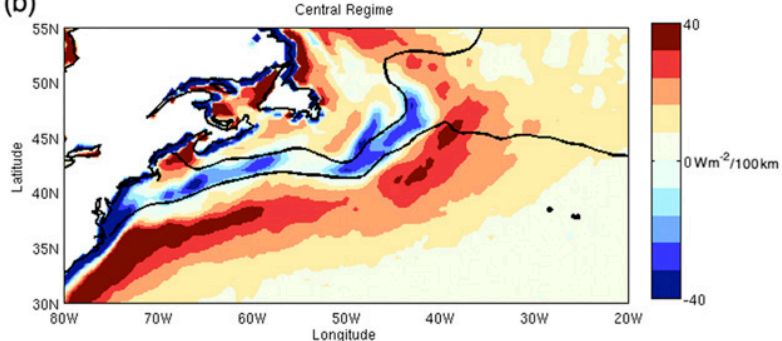

(c)

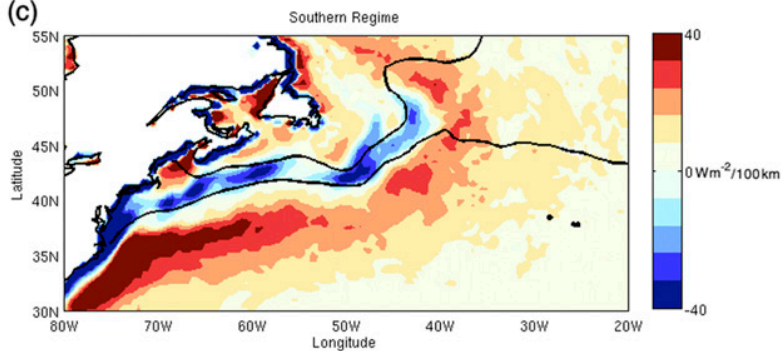

FIG. 8. The average cross-frontal sensible heat flux gradient experienced by an atmospheric cold front at any given location in each regime. Negative (positive) values indicate that the crossfrontal sensible heat flux gradient on average acts to strengthen (dampen) passing atmospheric cold fronts at that location. The mean SST contours in NCEP-CFSR are plotted in black for $6^{\circ}$ and $14^{\circ} \mathrm{C}$. The land has been marked in white.

Nevertheless, when one considers the anomalies (defined as regime value minus time mean such that negative anomalies imply stronger strengthening/weaker damping) in cross-atmospheric frontal surface sensible heat flux gradient (Fig. 9), one can clearly see noticeable differences. In particular, in the southern EDJ regime, there is considerably stronger strengthening/weaker damping experienced by atmospheric cold fronts across the entire Gulf Stream front, coinciding with positive anomalies in atmospheric frontal frequency (see Figs. 5 and 7).

The influence of this change in strengthening/damping on the associated frontal circulation can be clearly seen in Fig. 10, which illustrates the anomalies (defined as regime minus time mean) in frontal divergence at $900 \mathrm{hPa}$ (i.e., divergence specifically identified only when atmospheric fronts are detected) in each EDJ regime. Focusing in particular on the southern EDJ (a)

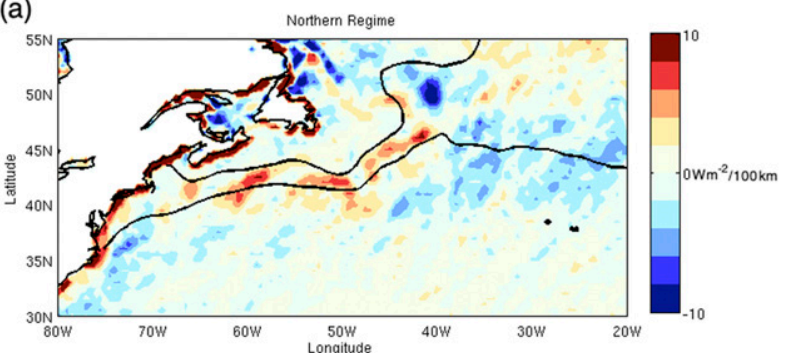

(b)

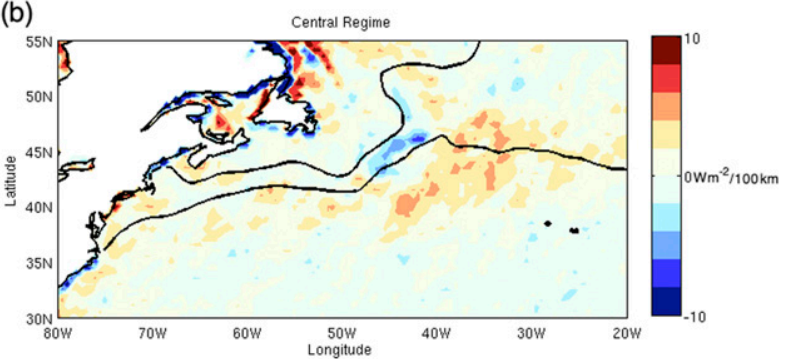

(c)

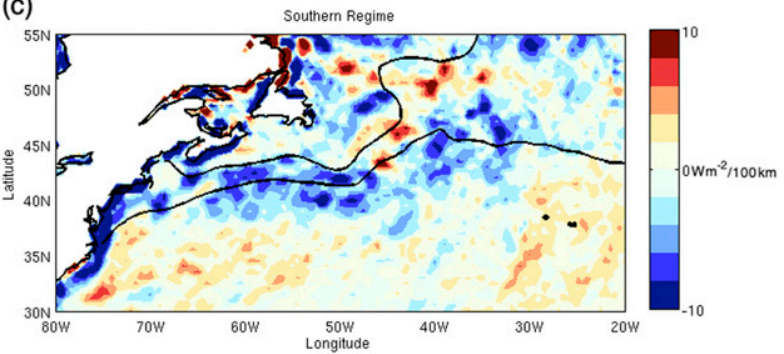

FIG. 9. Anomalies in cross-frontal sensible heat flux gradient experienced by an atmospheric cold front in each regime compared to the mean climatological cross-frontal sensible heat flux experienced by an atmospheric cold front. Anomalies are calculated as regime minus mean climatology. The mean SST contours in NCEPCFSR are plotted in black for $6^{\circ}$ and $14^{\circ} \mathrm{C}$. The land has been marked in white.

regime, one observes a notable increase in atmospheric frontal convergence (i.e., negative anomalies) toward the warm side of the Gulf Stream. Values more negative than $-0.8 \times 10^{-5} \mathrm{~s}^{-1}$ are significant to $90 \%$ (using the two-sample Student's $t$ test) across the basin. Furthermore, this increase in atmospheric frontal convergence broadly extends downstream. This eastward shift of the enhanced frontal convergence from the Gulf Stream is expected in part due to the time scale one might expect from a thermal air-sea interaction mechanism such as TDS ( $\sim 1$ day with a front traveling at, say, $10 \mathrm{~m} \mathrm{~s}^{-1}$ ). In addition, the frontal air-sea interaction associated with TDS is relatively weak away from the Gulf Stream, and so one can expect the anomalies to be maintained downstream. It is noted that negative values could also indicate a decrease in frontal divergence; however, consideration of the $900-\mathrm{hPa}$ time-mean 
(a)

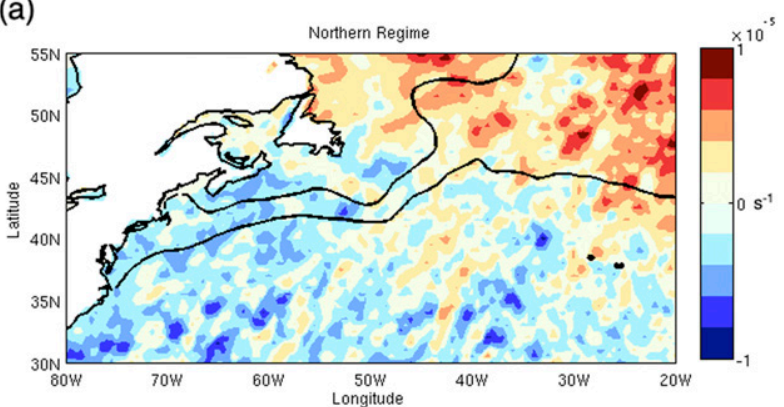

(b)

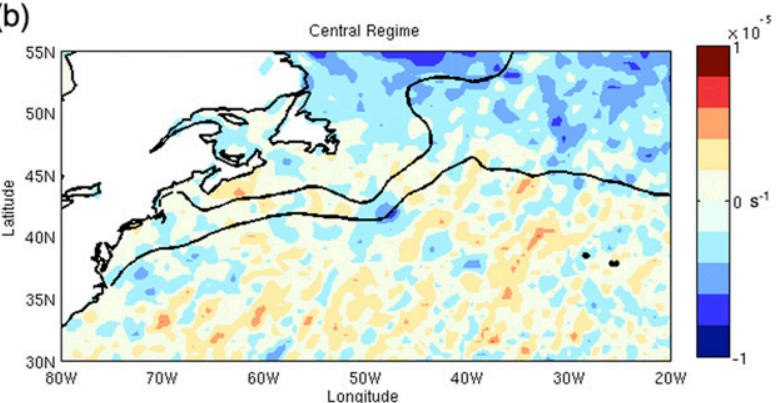

(c)

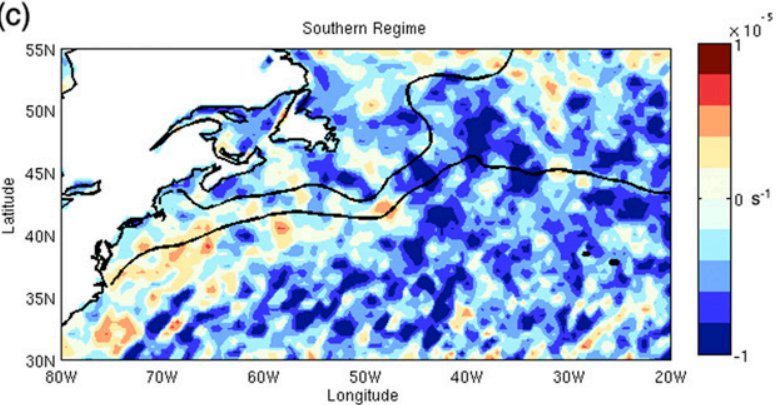

FIG. 10. Anomalies in atmospheric frontal divergence at $900 \mathrm{hPa}$ calculated as regime minus mean climatology. The mean SST contours in NCEP-CFSR are plotted in black for $6^{\circ}$ and $14^{\circ} \mathrm{C}$. The land has been marked in white.

frontal divergence as in Fig. 2a in Parfitt and Seo (2018) illustrates why this is not the case-on average convergence is found at atmospheric fronts everywhere.

As discussed earlier, while Parfitt and Seo (2018) showed that atmospheric fronts were responsible for setting the strong band of time-mean wind convergence on the warm side of the Gulf Stream front, it was only hypothesized that this was associated with the local strengthening of atmospheric cold fronts due to TDS. This hypothesis is confirmed in Fig. 11, which illustrates the contribution of atmospheric fronts in each EDJ regime to the time-mean wind convergence at $900 \mathrm{hPa}$ (calculated as the average frontal divergence in each regime multiplied by the atmospheric frontal frequency in that regime). As the contribution to the time-mean convergence from situations in which atmospheric (a)

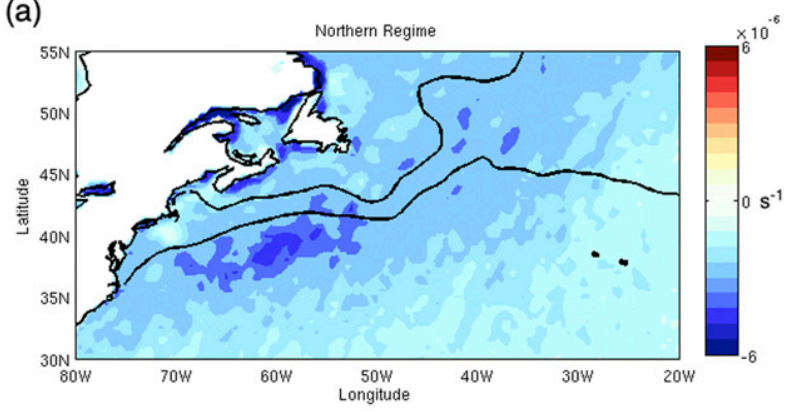

(b)

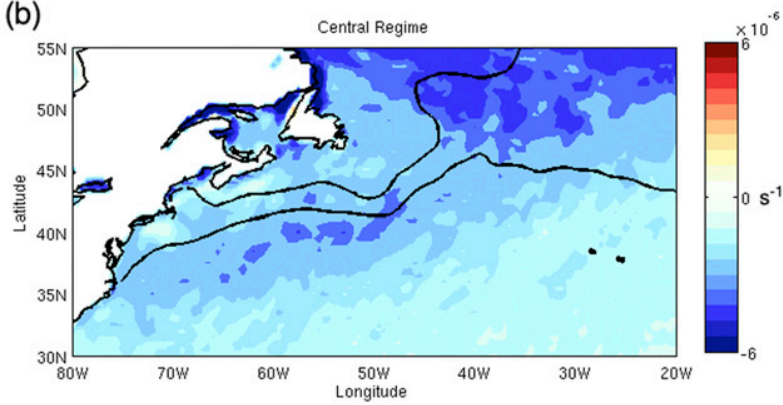

(c)

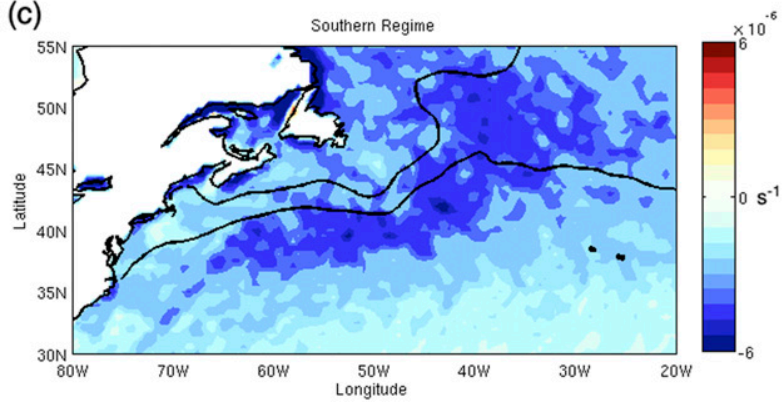

FIG. 11. Contribution of atmospheric fronts in each EDJ regime to the time-mean wind divergence at $900 \mathrm{hPa}$ (calculated as the average frontal divergence in each regime multiplied by the atmospheric frontal frequency in that regime).

fronts are not present is negligible (Parfitt and Seo 2018) in each EDJ regime (not shown), one can clearly deduce that the strong band of time-mean near-surface wind convergence on the warm side of the SST front is not only associated with atmospheric fronts, but primarily with atmospheric fronts in the southern EDJ regime (in which the EDJ was located only $19 \%$ of the time) due to enhanced frontal strengthening from TDS.

\section{Variation of midtropospheric and upper-level pressure vertical velocity with EDJ latitude}

Given that atmospheric fronts set the time-mean nearsurface wind convergence in the Gulf Stream region (Parfitt and Seo 2018) and can have considerable vertical structure, it is also reasonable to hypothesize that 
(a)

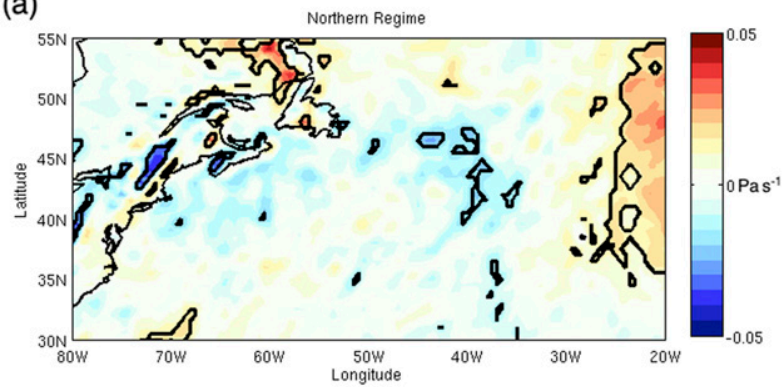

(b)

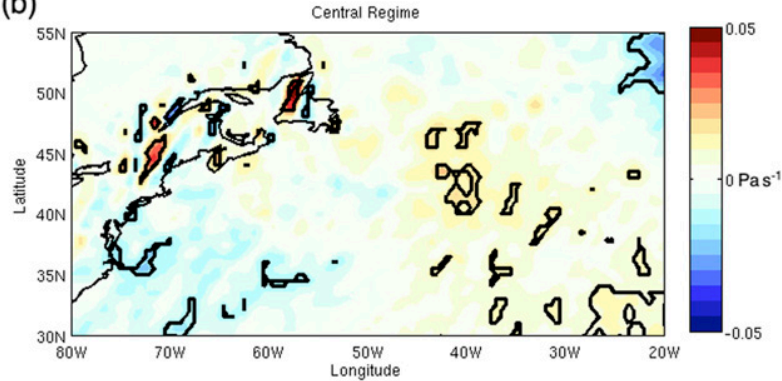

(c)

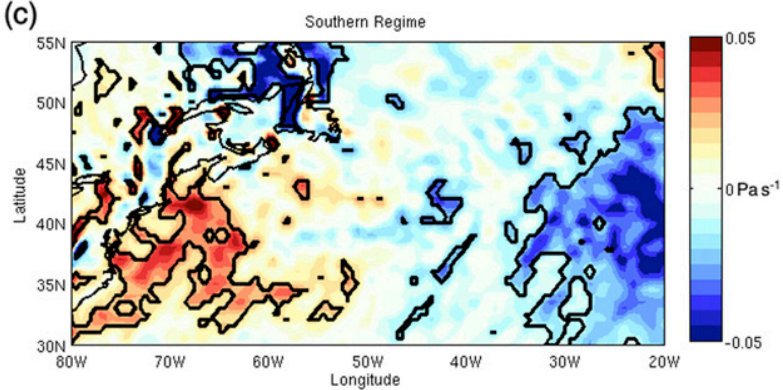

FIG. 12. Anomalies in pressure vertical velocity at $600 \mathrm{hPa}$ calculated as regime minus mean climatology (i.e., negative values imply either weaker subsidence or stronger ascent in that regime than on average). Thick black contours illustrate where the twosample Student's $t$ test indicates significance at $90 \%$.

changes in the near-surface frontal convergence may result in significant anomalies in the time-mean ascent throughout the depth of the troposphere, in particular when the EDJ is in its southern regime. For atmospheric fronts (except those that are quasi-stationary, which are rare across the Gulf Stream region; Berry et al. 2011), typical translation speeds are $\sim 10 \mathrm{~m} \mathrm{~s}^{-1}$, while typical magnitudes of ascent are $\sim 0.1 \mathrm{~Pa} \mathrm{~s}^{-1}$. One would therefore expect $\sim 1000 \mathrm{~km}$ horizontal displacement of the atmospheric front before surface convergence anomalies ascend by $\sim 100 \mathrm{hPa}$. Figure 12 illustrates anomalies (defined again as regime minus time mean) in pressure vertical velocity at $600 \mathrm{hPa}$ in each regime. Black contours mark where the two-sample Student's $t$ test indicates significance at $90 \%$. In the southern EDJ regime in particular, $\sim 3000 \mathrm{~km}$ downstream of the Gulf Stream spatially consistent broad regions of statistically significant enhanced ascent (or weakened descent) are located at $600 \mathrm{hPa}$. The magnitude of downstream displacement is consistent with the translational speed and ascent associated with near-surface atmospheric frontal convergence anomalies that are being driven by the Gulf Stream, suggesting that the impact of enhanced frontal convergence resulting from TDS extends far above the atmospheric boundary layer. The corresponding anomalies in pressure vertical velocity are also shown at $300 \mathrm{hPa}$ in Fig. S2.

It is noted that statistically significant positive anomalies in pressure vertical velocity are also identified off the eastern coast of the United States in the southern EDJ regime, and east of $\sim 30^{\circ} \mathrm{W}$ in the northern EDJ regime, associated with a significant decrease in ascent (or increase in descent). Comparison with Fig. 10 illustrates that these decreases in ascent are spatially consistent with reduced frontal convergence at $900 \mathrm{hPa}$, suggesting changes in surface atmospheric frontal circulation may be contributing once again. Unfortunately, both the positioning of the decrease in ascent near the coastline in the southern EDJ regime and the high degree of noise in the cross-atmospheric frontal surface sensible heat flux gradient in the northern EDJ regime make it difficult in the present analysis to definitively attribute these particular surface frontal convergence anomalies to surface thermal frontal air-sea interaction processes. It is therefore noted that while TDS as a mechanism has been shown to heavily influence nearsurface atmospheric frontal convergence with consistent impacts throughout the depth of the troposphere, further studies (e.g., modeling studies or explicitly accounting for land-atmosphere interactions) are required to fully quantify the relative processes behind the basinwide variability of near-surface atmospheric fronts.

\section{Summary}

In this paper, the relationship between the North Atlantic EDJ and atmospheric fronts was explored first. By considering three regimes of the EDJ, referred to as northern, central, and southern (defined respectively as latitudes greater than $52.5^{\circ} \mathrm{N}$, between $40^{\circ}$ and $52.5^{\circ} \mathrm{N}$, and less than $40^{\circ} \mathrm{N}$ ), it was found that the frequency of atmospheric fronts at both 900 and $600 \mathrm{hPa}$ is highly related to the latitude of the EDJ, with atmospheric fronts more frequently observed at the latitude of the EDJ. In some locations, changes in atmospheric frontal frequency between each regime and the time mean were as large as $50 \%$.

The implications of these observations were subsequently considered in the context of the time-mean 
near-surface wind convergence, known to reflect the meander of the Gulf Stream (Minobe et al. 2008). This was primarily motivated by recent studies showing that it is actually atmospheric fronts that are responsible for the strong band of convergence found in the time mean toward the warm side of the Gulf Stream (Parfitt and Seo 2018). Analysis of the contribution of atmospheric fronts to the time-mean near-surface wind convergence in each regime illustrated that it is the southern EDJ regime, where atmospheric frontal frequency is maximized over the Gulf Stream, that is primarily responsible for the strong band of time-mean convergence toward the warm side of the Gulf Stream.

In an attempt to explain this enhanced near-surface wind convergence on the warm side of the Gulf Stream in the southern EDJ regime, the only currently existing mechanistic theory linking strong SST fronts to atmospheric fronts was investigated. Derived from previous modeling (Parfitt et al. 2016) and reanalysis-based (Parfitt et al. 2017a) studies, and termed "thermal damping and strengthening" (TDS), this theory has shown the response of atmospheric fronts to Gulf Stream perturbations to be primarily associated with atmospheric cold fronts specifically and driven by cross-atmospheric frontal surface sensible heat flux gradients, which are particularly strong over high SST gradients such as the Gulf Stream front. Here, it was found that in comparison to the atmospheric frontal frequency variability, the TDS mechanism was relatively independent of the EDJ latitude. This suggests that the surface sensible heat flux gradients experienced by passing atmospheric cold fronts is primarily set by the underlying ocean.

Nevertheless, consideration of the cross-atmospheric frontal surface sensible heat flux gradient anomalies still illustrated notable differences. In particular, in the southern EDJ regime, considerably stronger strengthening/weaker damping is shown to be experienced by atmospheric cold fronts across the entire Gulf Stream front, coinciding with positive anomalies in atmospheric frontal frequency. Furthermore, considerably stronger frontal convergences are identified at $900 \mathrm{hPa}$ in the southern EDJ regime on the warm side of the Gulf Stream and farther downstream than on average. This suggests that the dominating influence of the southern EDJ regime on the time-mean near-surface wind convergence toward the warm side of the Gulf Stream is a result of enhanced atmospheric cold-frontal strengthening via TDS.

Furthermore, in the southern EDJ regime, downstream of the Gulf Stream front, a broad region of statistically significantly stronger ascent/weaker descent can be found at both 600 and $300 \mathrm{hPa}$, suggesting that this increase in surface atmospheric frontal convergence may extend throughout the depth of the troposphere. This hints that surface heat flux processes associated with the Gulf Stream can impact deep into the troposphere through their influence on atmospheric fronts, and that this air-sea coupling is enhanced when the EDJ is located at more southerly latitudes. It is noted that several other statistically significant vertical velocity anomalies were also identified. Although they were also shown to be consistent with surface frontal convergence anomalies, it was not possible from the present analysis to directly associate them with TDS.

Nevertheless, these results provide additional motivation for correcting known jet biases in current climate models, as the representation of the EDJ in its southern regime is known to be more poorly represented than in other regimes, resulting in poor simulation of highimpact events such as Greenland blocking (Davini and Cagnazzo 2014; Kwon et al. 2018). Last, it was discussed in the introduction that the latitudinal variation of the EDJ has been strongly correlated with various weather indices such as the NAO. Given these results suggest that certain EDJ latitudes may result in a deeper oceanic influence on the atmosphere, this also suggests that certain large-scale weather indices may also favor enhanced air-sea coupling in the North Atlantic. This would add to the recent work stressing the need for suitably high resolution SST for the correct representation of the most severe North Atlantic weather events (e.g., Vannière et al. 2017; Sheldon et al. 2017).

Acknowledgments. For part of this study, R. P. was funded by the Weston Howland Jr. postdoctoral scholarship at Woods Hole Oceanographic Institution. We gratefully acknowledge the support to Y.-O. K. from the NOAA CPO Climate Variability and Predictability program (NA13OAR4310139), the DOE Regional and Global Model Analysis program (DE-SC0014433 and DE-SC0019492), and the NSF AGS Climate and Large-scale Dynamics program and OCE Physical Oceanography program (AGS-1355339). We thank NCAR for allowing access to the NCEP-CFSR dataset, accessible at https://rda.ucar.edu. We thank the editor Hisashi Nakamura and the three reviewers whose comments have helped greatly improve the manuscript.

\section{REFERENCES}

Barsugli, J. J., and D. S. Battisti, 1998: The basic effects of atmosphere-ocean thermal coupling on midlatitude variability. J. Atmos. Sci., 55, 477-493, https://doi.org/10.1175/15200469(1998)055<0477:TBEOAO > 2.0.CO;2.

Berry, G., M. J. Reeder, and C. Jakob, 2011: A global climatology of atmospheric fronts. Geophys. Res. Lett., 38, L04809, https:// doi.org/10.1029/2010GL046451. 
Bishop, S. P., R. J. Small, F. O. Bryan, and R. A. Tomas, 2017: Scale dependence of midlatitude air-sea interaction. J. Climate, $\mathbf{3 0}$, 8207-8221, https://doi.org/10.1175/JCLI-D-17-0159.1.

Cassou, C., L. Terray, J. W. Hurrell, and C. Deser, 2004: North Atlantic winter climate regimes: Spatial asymmetry, stationarity with time, and oceanic forcing. J. Climate, 17, 1055-1068, https://doi.org/10.1175/1520-0442(2004)017<1055: NAWCRS $>2.0 . C O ; 2$.

Catto, J. L., C. Jakob, G. Berry, and N. Nicholls, 2012: Relating global precipitation to atmospheric fronts. Geophys. Res. Lett., 39, L10805, https://doi.org/10.1029/2012GL051736.

Ciasto, L. M., and D. W. Thompson, 2004: North Atlantic atmosphere-ocean interaction on intraseasonal time scales. J. Climate, 17, 1617-1621, https://doi.org/10.1175/1520-0442(2004) 017<1617:NAAIOI > 2.0.CO;2.

Davini, P., and C. Cagnazzo, 2014: On the misinterpretation of the North Atlantic Oscillation in CMIP5 models. Climate Dyn., 43, 1497-1511, https://doi.org/10.1007/s00382-013-1970-y.

Deser, C., and M. S. Timlin, 1997: Atmosphere-ocean interaction on weekly timescales in the North Atlantic and Pacific. J. Climate, 10, 393-408, https://doi.org/10.1175/1520-0442(1997) 010<0393:AOIOWT >2.0.CO;2.

Feliks, Y., M. Ghil, and E. Simonnet, 2004: Low-frequency variability in the midlatitude atmosphere induced by an oceanic thermal front. J. Atmos. Sci., 61, 961-981, https://doi.org/ 10.1175/1520-0469(2004)061<0961:LVITMA > 2.0.CO;2.

,$- \ldots$, and,- 2007 : Low-frequency variability in the midlatitude baroclinic atmosphere induced by an oceanic thermal front. J. Atmos. Sci., 64, 97-116, https://doi.org/10.1175/ JAS3780.1.

Frankignoul, C., and K. Hasselmann, 1977: Stochastic climate models, Part II: Application to sea-surface temperature anomalies and thermocline variability. Tellus, 29, 289-305, https://doi.org/10.3402/tellusa.v29i4.11362.

_ , P. Müller, and E. Zorita, 1997: A simple model of the decadal response of the ocean to stochastic wind forcing. J. Phys. Oceanogr., 27, 1533-1546, https://doi.org/10.1175/1520-0485(1997) 027<1533:ASMOTD>2.0.CO;2

Hayes, S. P., M. J. McPhaden, and J. M. Wallace, 1989: The influence of sea-surface temperature on surface wind in the eastern equatorial Pacific: Weekly to monthly variability. J. Climate, 2 , 1500-1506, https://doi.org/10.1175/1520-0442(1989)002<1500: TIOSST $>2.0 . \mathrm{CO} ; 2$.

Hewitt, H. T., and Coauthors, 2017: Will high-resolution global ocean models benefit coupled predictions on short-range to climate timescales? Ocean Modell., 120, 120-136, https:// doi.org/10.1016/j.ocemod.2017.11.002.

Hewson, T. D., 1998: Objective fronts. Meteor. Appl., 5, 37-65, https://doi.org/10.1017/S1350482798000553.

Hirata, H., R. Kawamura, M. K. Yoshioka, M. Nonaka, and K. Tsuboki, 2019: Key role of the Kuroshio current in the formation of frontal structure of an extratropical cyclone associated with heavy precipitation. J. Geophys. Res. Atmos., 124, 6143-6156, https://doi.org/10.1029/2018JD029578.

Kobashi, F., S. P. Xie, N. Iwasaka, and T. T. Sakamoto, 2008: Deep atmospheric response to the North Pacific oceanic subtropical front in spring. J. Climate, 21, 5960-5975, https://doi.org/ 10.1175/2008JCLI2311.1.

Kwon, Y. O., A. Camacho, C. Martinez, and H. Seo, 2018: North Atlantic winter eddy-driven jet and atmospheric blocking variability in the Community Earth System Model version 1 Large Ensemble simulations. Climate Dyn., 51, 3275-3289, https://doi.org/10.1007/S00382-018-4078-6.
Lee, R. W., T. J. Woollings, B. J. Hoskins, K. D. Williams, C. H. O'Reilly, and G. Masato, 2018: Impact of Gulf Stream SST biases on the global atmospheric circulation. Climate Dyn., 51, 3369-3387, https://doi.org/10.1007/s00382-018-4083-9.

Lindzen, R. S., and S. Nigam, 1987: On the role of sea surface temperature gradients in forcing low-level winds and convergence in the tropics. J. Atmos. Sci., 44, 2418-2436, https://doi.org/10.1175/ 1520-0469(1987)044<2418:OTROSS > 2.0.CO;2.

Liu, C., and E. A. Barnes, 2015: Extreme moisture transport into the Arctic linked to Rossby wave breaking. J. Geophys. Res. Atmos., 120, 3774-3788, https://doi.org/10.1002/2014JD022796.

Madonna, E., C. Li, C. M. Grams, and T. Woollings, 2017: The link between eddy-driven jet variability and weather regimes in the North Atlantic-European sector. Quart. J. Roy. Meteor. Soc., 143, 2960-2972, https://doi.org/10.1002/qj.3155.

Masunaga, R., H. Nakamura, T. Miyasaka, K. Nishii, and Y. Tanimoto, 2015: Separation of climatological imprints of the Kuroshio Extension and Oyashio fronts on the wintertime atmospheric boundary layer: Their sensitivity to SST resolution prescribed for atmospheric reanalysis. J. Climate, 28, 1764-1787, https://doi.org/10.1175/JCLI-D-14-00314.1.

Minobe, S., A. Kuwano-Yoshida, N. Komori, S.-P. Xie, and R. J. Small, 2008: Influence of the Gulf Stream on the troposphere. Nature, 452, 206-209, https://doi.org/10.1038/nature06690.

M. Miyashita, A. Kuwano-Yoshida, H. Tokinaga, and S.-P. Xie, 2010: Atmospheric response to the Gulf Stream: Seasonal variations. J. Climate, 23, 3699-3719, https://doi.org/10.1175/ 2010JCLI3359.1.

Nkwinkwa Njouodo, A. S., S. Koseki, N. Keenlyside, and M. Rouault, 2018: Atmospheric signature of the Agulhas Current. Geophys. Res. Lett., 45, 5185-5193, https://doi.org/ 10.1029/2018GL077042.

O'Neill, L. W., T. Haack, D. B. Chelton, and E. Skyllingstad, 2017: The Gulf Stream convergence zone in the time-mean winds. J. Atmos. Sci., 74, 2383-2412, https://doi.org/10.1175/JAS-D16-0213.1.

Parfitt, R., 2014: Extreme air-sea interactions over the Gulf Stream. Ph.D. dissertation, Imperial College London, 189 pp. , and A. Czaja, 2016: On the contribution of synoptic transients to the mean atmospheric state in the Gulf Stream region. Quart. J. Roy. Meteor. Soc., 142, 1554-1561, https://doi.org/ 10.1002/qj.2689.

— , and H. Seo, 2018: A new framework for near-surface wind convergence over the Kuroshio Extension and Gulf Stream in wintertime: The role of atmospheric fronts. Geophys. Res. Lett., 45, 9909-9918, https://doi.org/10.1029/2018GL080135.

— A. Czaja, S. Minobe, and A. Kuwano-Yoshida, 2016: The atmospheric frontal response to SST perturbations in the Gulf Stream region. Geophys. Res. Lett., 43, 2299-2306, https:// doi.org/10.1002/2016GL067723.

, - $\longrightarrow$, and Y. O. Kwon, 2017a: The impact of SST resolution change in the ERA-Interim reanalysis on wintertime Gulf Stream frontal air-sea interaction. Geophys. Res. Lett., 44, 3246-3254, https://doi.org/10.1002/2017GL073028.

, - - and H. Seo, 2017b: A simple diagnostic for the detection of atmospheric fronts. Geophys. Res. Lett., 44, 4351-4358, https://doi.org/10.1002/2017GL073662.

Saha, S., and Coauthors, 2010: The NCEP Climate Forecast System Reanalysis. Bull. Amer. Meteor. Soc., 91, 1015-1057, https:// doi.org/10.1175/2010BAMS3001.1.

Santos, J. A., T. Woollings, and J. G. Pinto, 2013: Are the winters 2010 and 2012 archetypes exhibiting extreme opposite behavior of the North Atlantic jet stream? Mon. Wea. 
Rev., 141, 3626-3640, https://doi.org/10.1175/MWR-D-1300024.1 .

Schemm, S., I. Rudeva, and I. Simmonds, 2015: Extratropical fronts in the lower troposphere-Global perspectives obtained from two automated methods. Quart. J. Roy. Meteor. Soc., 141, 1686-1698, https://doi.org/10.1002/qj.2471.

Seager, R., D. S. Battisti, J. Yin, N. Gordon, N. Naik, A. C. Clement, and M. A. Cane, 2002: Is the Gulf Stream responsible for Europe's mild winters? Quart. J. Roy. Meteor. Soc., 128, 2563-2586, https://doi.org/10.1256/qj.01.128.

Sheldon, L., A. Czaja, B. Vannière, C. Morcrette, B. Sohet, M. Casado, and D. Smith, 2017: A 'warm path' for Gulf Stream-troposphere interactions. Tellus, 69A, 1299397, https://doi.org/10.1080/16000870.2017.1299397.

Siqueira, L., and B. P. Kirtman, 2016: Atlantic near-term climate variability and the role of a resolved Gulf Stream. Geophys. Res. Lett., 43, 3964-3972, https://doi.org/10.1002/ 2016 GL068694.

Small, R. J., R. Msadek, Y. O. Kwon, J. F. Booth, and C. Zarzycki, 2018: Atmosphere surface storm track response to resolved ocean mesoscale in two sets of global climate model experiments. Climate Dyn., 52, 2067-2089, https://doi.org/10.1007/ S00382-018-4237-9.

Smirnov, D., M. Newman, M. A. Alexander, Y. O. Kwon, and C. Frankignoul, 2015: Investigating the local atmospheric response to a realistic shift in the Oyashio sea surface temperature front. J. Climate, 28, 1126-1147, https://doi.org/10.1175/ JCLI-D-14-00285.1.

Solman, S. A., and I. Orlanski, 2010: Subpolar high anomaly preconditioning precipitation over South America. J. Atmos. Sci., 67, 1526-1542, https://doi.org/10.1175/2009JAS3309.1. , and - 2014: Poleward shift and change of frontal activity in the Southern Hemisphere over the last 40 years. J. Atmos. Sci., 71, 539-552, https://doi.org/10.1175/JAS-D-13-0105.1.
Tokinaga, H., Y. Tanimoto, S. P. Xie, T. Sampe, H. Tomita, and H. Ichikawa, 2009: Ocean frontal effects on the vertical development of clouds over the western North Pacific: In situ and satellite observations. J. Climate, 22, 4241-4260, https:// doi.org/10.1175/2009JCLI2763.1.

Vannière, B., A. Czaja, H. Dacre, and T. Woollings, 2017: A “cold path" for the Gulf Stream-troposphere connection. J. Climate, 30, 1363-1379, https://doi.org/10.1175/JCLI-D-15-0749.1.

Vautard, R., 1990: Multiple weather regimes over the North Atlantic: Analysis of precursors and successors. Mon. Wea. Rev., 118, 2056-2081, https://doi.org/10.1175/1520-0493(1990) 118<2056:MWROTN>2.0.CO;2.

Wai, M. M. K., and S. A. Stage, 1989: Dynamical analyses of marine atmospheric boundary layer structure near the Gulf Stream oceanic front. Quart. J. Roy. Meteor. Soc., 115, 29-44, https:// doi.org/10.1002/qj.49711548503.

Wallace, J. M., T. P. Mitchell, and C. Deser, 1989: The influence of sea-surface temperature on surface wind in the eastern equatorial Pacific: Seasonal and interannual variability. J. Climate, 2, 1492-1499, https://doi.org/10.1175/1520-0442(1989)002<1492: TIOSST $>2.0 . \mathrm{CO} ; 2$.

Wills, S. M., D. W. Thompson, and L. M. Ciasto, 2016: On the observed relationships between variability in Gulf Stream sea surface temperatures and the atmospheric circulation over the North Atlantic. J. Climate, 29, 3719-3730, https://doi.org/10.1175/JCLI-D-15-0820.1.

Woollings, T., A. Hannachi, and B. Hoskins, 2010: Variability of the North Atlantic eddy-driven jet stream. Quart. J. Roy. Meteor. Soc., 136, 856-868, https://doi.org/10.1002/qj.625.

C. Czuchnicki, and C. Franzke, 2014: Twentieth century North Atlantic jet variability. Quart. J. Roy. Meteor. Soc., 140, 783-791, https://doi.org/10.1002/qj.2197.

— , and Coauthors, 2018: Daily to decadal modulation of jet variability. J. Climate, 31, 1297-1314, https://doi.org/10.1175/ JCLI-D-17-0286.1. 